\title{
7,8-Dihydroxyflavone, a Tropomyosin-Kinase Related Receptor B Agonist, Produces Fast-Onset Antidepressant-Like Effects in Rats Exposed to Chronic Mild Stress
}

\author{
Hsin-An Chang ${ }^{1}$, Ying-Hsiu Wang ${ }^{2}$, Che-Se Tung ${ }^{2,3}$, Chin-Bin Yeh ${ }^{1}$, and Yia-Ping Liu', ${ }^{1,2}$ \\ 'Department of Psychiatry, Tri-Service General Hospital, National Defense Medical Center, Taipei, Taiwan \\ 2Department of Physiology and Biophysics, National Defense Medical Center, Taipei, Taiwan \\ ${ }^{3}$ Division of Medical Research and Education, Cheng Hsin General Hospital, Taipei, Taiwan
}

Objective Brain-derived neurotrophic factor (BDNF) and its specific receptor, tropomyosin-related kinase (TrkB), play important roles in treating depression. In this experiment, we examined whether 7,8-dihydroxyflavone, a novel potent TrkB agonist, could reverse the behavioral and biochemical abnormalities induced by the chronic mild stress (CMS) paradigm in rats.

Methods SD rats were exposed to a battery of stressors for 56 days. 7,8-dihydroxyflavone ( 5 and $20 \mathrm{mg} / \mathrm{kg})$ were administered intraperitoneally during the last 28 days of the CMS paradigm. Rats were tested in sucrose consumption test (SCT), forced-swimming test (FST) and elevated T-maze (ETM). Serum corticosterone levels and hippocampal BDNF levels of the rats were measured.

Results Four-week CMS on the rats induced their depression-like behavior in SCT. The CMS-reduced sucrose consumption was reversed starting from 7 days after the 7,8-dihydroxyflavone $(20 \mathrm{mg} / \mathrm{kg})$ treatment and remained across the subsequent treatment regime. 7,8-dihydroxyflavone, when given at $5 \mathrm{mg} / \mathrm{kg}$ for 3 weeks, reduced the immobility time in the FST in the CMS-subjected rats. Additionally, the 4 -week treatment with 7,8-dihydroxyflavone $(20 \mathrm{mg} / \mathrm{kg})$ attenuated the CMS-induced increase in anxiety-like behavior in the ETM. For the CMS-subjected rats, 7,8-dihydroxyflavone treatment dose-dependently reduced their serum corticosterone levels but increased their hippocampal BDNF levels only at $5 \mathrm{mg} / \mathrm{kg}$.

Conclusion 7,8-dihydroxyflavone was beneficial for both depression and anxiety-like behaviors, and may exert fast-onset antidepressant effects. This provides a new insight into the pharmacological management of depression. Psychiatry Investig 2016;13(5):531-540

Key Words Depression, Anxiety, Chronic mild stress, TrkB agonist, BDNF.

\section{INTRODUCTION}

Brain-derived neurotrophic factor (BDNF), involved in the development and activity-dependent regulation of neuronal structures, is the most prominent member of the neurotrophin family. ${ }^{1}$ Accumulating evidence suggests that BDNF may be involved in the pathophysiology of major depressive disorder and that the action of antidepressants could be mediated by their action on the BDNF system..$^{2-5}$ Specifically, depressed pa-

Received: September 26, 2015 Revised: December 13, 2015

Accepted: December 16, 2015 Available online: April 6, 2016

$\triangle$ Correspondence: Yia-Ping Liu, MD, PhD

Department of Physiology and Biophysics, National Defense Medical Center, Department of Psychiatry, Tri-Service General Hospital No.161, Section 6, Min-

Chuan East Road, Taipei 114, Taiwan, Republic of China

Tel: 886-2-87923100, ext 18614, Fax: 886-2-87923153

E-mail: yiaping@ndmctsgh.edu.tw

(c) This is an Open Access article distributed under the terms of the Creative Commons Attribution Non-Commercial License (http://creativecommons.org/licenses/bync/3.0) which permits unrestricted non-commercial use, distribution, and reproduction in any medium, provided the original work is properly cited. tients have low levels of BDNF, which can be reversed by the treatment with antidepressants. ${ }^{6}$ BDNF exerts its effects by binding to tropomyosin-kinase related receptor B (TrkB). ${ }^{7-9}$ TrkB signals through mitogen-activated protein kinase (MAPK), phosphatidylinositol 3-kinase (PI3K) and phospholipase $\mathrm{C}-\gamma 1$, and is important for the neurogenesis, synaptic function and plasticity in the adult nervous system. ${ }^{10,11}$

Since BDNF has poor blood-brain barrier penetration and a short half life, ${ }^{12}$ specific small molecule TrkB agonists capable of being administered systemically and initiating TrkB activation with equal potency to BDNF, have been developed recently. ${ }^{13,14}$ Of note, one recently identified high affinity $\operatorname{TrkB}$ agonist, 7,8-dihydroxyflavone (DHF), has shown promising protective effects in mouse models of aging, Parkinson disease, and Alzheimer disease. ${ }^{14-17}$ Growing numbers of researchers recently sought to focus on the role of 7,8-DHF in treating depression. ${ }^{18,19}$ Chronic mild stress (CMS) paradigm is a wellknown animal model of depression that causes stressed rats to 
exhibit depressive-like behaviors, elevated serum corticosterone levels, and decreased hippocampus BDNF levels. ${ }^{20,21}$ The current study aimed to investigate whether 7,8-DHF treatment on rats can reverse the CMS induced depressive-like behaviors and biochemical alterations.

Anxiety is also a frequent and well-known consequence of chronic stress. Considerable research shows that the coexistence of depression with anxiety disorders is rather a rule than an exception, ${ }^{22}$ even though depression and anxiety are distinct psychiatric disorders. It has been demonstrated that BDNF is involved in both the pathogenesis and treatment of anxiety disorders. ${ }^{23,24}$ To date, a small body of research has examined the anxiolytic effect of 7,8-DHF; for example, 7,8-DHF was reported to enhance the extinction of fear in animal models of posttraumatic stress disorder (PTSD). ${ }^{25,26}$ However, a recent report failed to demonstrate the ability of 7,8-DHF to alter rats'anxiety-like behavior on an elevated plus maze. ${ }^{27}$ In the present study, we also investigated the anxiolytic effect of 7,8DHF in CMS-subjected rats.

\section{METHODS}

\section{Animals}

Twenty-eight male Sprague-Dawley (SD) rats (BioLASCO Taiwan Co. Ltd., Taipei, Taiwan) were used. All rats were housed in groups of 3 and in the same temperature and humidity-controlled holding facility $\left(22 \pm 2^{\circ} \mathrm{C}\right)$ on a $12 \mathrm{~h}$ light/ dark cycle (lights on at 07:00). All animals received food and water ad libitum. The rats were allowed 1 week to acclimate to the laboratory surroundings before the beginning of the experimentation and none of them were tested until the age of 8 weeks old. All experimental procedures were evaluated and approved by the animal care committee of the National Defense Medical Center (Taiwan) with the permission code IACUC-04-156. All efforts were made to reduce the number of animals used and to minimize animal suffering during the experiments. All measurements were performed by individuals blind to the treatment received by the rats.

\section{Apparatus}

The elevated T-maze (ETM) was made of wood and had three arms of equal dimensions $\left(50 \times 12 \mathrm{~cm}^{2}\right)$. One of the arms was enclosed by walls that were $40 \mathrm{~cm}$ high, and was oriented perpendicularly to two opposed open arms. The whole apparatus was elevated $50 \mathrm{~cm}$ above the floor. To avoid falls, a $1 \mathrm{~cm}$ high Plexiglas rim surrounded the open arms. The open field was a round arena $\left(60 \mathrm{~cm}^{2}\right)$, with the floor divided into 12 parts, and walls that were $50 \mathrm{~cm}$ high. Luminosity at the level of the T-maze arms or at the open field center was $60 \mathrm{~lx}$. After the experimental session conducted with each animal, the
ETM and the open field were cleaned with a 10\% ethanol solution. In the ETM, the escape behavior, which mimics paniclike behavior, ${ }^{28,29}$ is induced by an ethologically relevant threatening stimulus: the exposure to an open and elevated space. In addition, inhibitory avoidance is considered a defensive reaction, which models generalized anxiety. ${ }^{28,29}$

\section{Drugs}

A selective TrkB receptor agonist, 7,8-dihydroxyflavone (Tokyo Chemical Industry Co. Ltd., Tokyo, Japan), ${ }^{14}$ was dissolved in phosphate-buffered saline containing 50\% dimethylsulfoxide (DMSO). 7,8-DHF or vehicle was injected intraperitoneally (i.p.) once daily from the time after the CMS treatment for four weeks until the end of the experiment. Rats were given the last dose of 7,8-DHF or vehicle 2 hours prior to sacrifice. The doses of 7,8-DHF employed in the current experiments were 5 and $20 \mathrm{mg} / \mathrm{kg}$.

\section{Experiment design}

The animals were trained to consume $2 \%$ sucrose solution in a 1-hour test that was performed twice a week (Figure 1A). Following the two-week sucrose consumption training, the sucrose intakes of the rats were obtained to allow the division of the rats into control group and the CMS group with both groups having similar sucrose intakes. The CMS group was exposed to stress for 4 weeks and subsequently to stress in combination with 7,8-DHF or vehicle treatment for 4 consecutive weeks. During the 8 -week CMS period, the rats were subjected to behavioral tests once a week (sucrose consumption test) and in week 0, 4, 6 (locomotor activity), 7 (forcedswimming test), and 8 (ETM) of CMS period. Two days after the CMS period ended, the animals were sacrificed and their blood and brain tissues were collected for biochemical analysis.

\section{Chronic mild stress}

The animals were divided into two matched groups and placed in separate rooms. The CMS procedure was adapted from the procedure described elsewhere ${ }^{30,31}$ with slight modifications. Briefly described here, all rats in the CMS group were housed in single cages and exposed to the following stressors in a randomized fashion throughout the 8 weeks experiment: 1) $24 \mathrm{~h}$ food deprivation; 2) $24 \mathrm{~h}$ water deprivation; 3) housing in a cage filled with an odor; 4) $45^{\circ}$ cage tilt and overnight illumination; 5) $24 \mathrm{~h}$ soiled cage $(200 \mathrm{~mL}$ water in $100 \mathrm{~g}$ sawdust bedding). Normal control rats were left undisturbed in their home cages.

\section{Measurement of body weight}

The body weight of each rat was measured weekly from week 0 (initial week) to week 8 , but was never recorded after 
the food or water deprivation-stressor of the CMS procedure.

\section{Locomotor activity}

Locomotor activity was measured using a computerized automated activity monitoring system (MED Associates, Inc., St. Albans, VT, USA). The system included four plexiglass chambers $\left(43 \times 43 \times 30 \mathrm{~cm}^{3}\right)$ equipped with an I/R array of 16 photodetectors and corresponding light sources that emitted photobeams $3 \mathrm{~cm}$ apart and $4.5 \mathrm{~cm}$ above the chamber floor. Travel distance was recorded at the assigned intervals and was controlled by the MED Associates software.

\section{Sucrose consumption test}

The methods for sucrose consumption test used to operationally define anhedonia, was adapted from the procedure described previously ${ }^{32}$ with slight modifications. The animals were first habituated to consume a palatable sucrose solution (2\%). The habituation period lasted 2 weeks. In this period, the sucrose test was made twice a week. Animals were food and water deprived 15 hours before the test, which was a 1-hour period with free access to a bottle of the sucrose solution.

\section{Forced-swimming test}

Forced-swimming test (FST) was performed between 9:30 A.M. and 1:00 P.M. Experiments were performed as described previously. ${ }^{33}$ Briefly described here, the rats were placed for 15 min into a $25 \mathrm{~cm}$ diameter $\times 50 \mathrm{~cm}$ height plastic cylinder, which was filled with $20-25^{\circ} \mathrm{C}$ water to a depth of $30 \mathrm{~cm}$. The rats were then removed, dried, and returned to their home cage. They were placed again in the cylinders $24 \mathrm{~h}$ later, and then a 5-min swim test was conducted and videotaped. Immobility was defined as the minimum movement required to passively keep the animal's head above the water without other motions. Climbing was defined as the upward-directed movement of the forepaws against the wall. The results are expressed as the amount of time (in seconds) that the animals spent immobile and climbing during the 5 -min test.

\section{Serum corticosterone levels}

The rats were killed between 0800 and 1100, during which time their blood samples from trunk vessels were collected into chilled tubes. Serum corticosterone was quantified by using a commercially available enzyme-linked immunosorbent assay Sandwich ELISA Kit (Caymanchem) according to the manufacturer's instructions. All samples were performed in duplicate.

\section{Hippocampal BDNF levels}

We choose to test BDNF levels in this brain region because numerous studies have suggested a link between BDNF in the hippocampus and stress-related depression-like behavior ${ }^{34,35}$ or the therapeutic effect of chronic antidepressant treatment. ${ }^{36,37}$ When the rats were killed, their brains were rapidly removed. Bilateral hippocampi were rapidly dissected and stored at $-80^{\circ} \mathrm{C}$. At the time of analysis, the samples were weighed, and BDNF was extracted as described previously. ${ }^{38}$ Two milliliters of lysis buffer (100 mM PIPES, $500 \mathrm{mM} \mathrm{NaCl}, 0.2 \%$ Triton $\mathrm{X}-100,0.1 \% \mathrm{NaN} 3,2 \% \mathrm{BSA}$, and $2 \mathrm{mM}$ EDTA) containing freshly prepared protease inhibitors ( $200 \mu \mathrm{M}$ PMSF, $0.3 \mu \mathrm{M}$ aprotinin, and $10 \mu \mathrm{M}$ leupeptin) were added to each sample. The samples were then sonicated by pulses at $1 \mathrm{~s}$ intervals for $15 \mathrm{~s}$. An additional $1 \mathrm{~mL}$ of lysis buffer was added, and the samples were then resonicated. All homogenates were centrifuged at $16,000 \times \mathrm{g}$ for $30 \mathrm{~min}$ at $4^{\circ} \mathrm{C}$, and supernatants were removed and frozen at $-20^{\circ} \mathrm{C}$ until assay. The concentration of hippocampal BDNF was quantified using the BDNF Sandwich ELISA kit (Abnova). The tissue samples and serial dilutions of BDNF standards were loaded in duplicate onto a 96well plate coated with primary antibodies. The plate was sealed and incubated for $90 \mathrm{mins}$ at $37^{\circ} \mathrm{C}$. After the wells were washed three times with $400 \mu \mathrm{L} /$ well of PBS, biotinylated antirat BDNF monoclonal antibody was added for $1 \mathrm{~h}$ at $37^{\circ} \mathrm{C}$. The plates were washed four times. Strepavidin-enzyme conjugate was added, and the plates were incubated for 30 mins. After further washing, tetramethylbenzidine chromagenic substrate was added and the reaction was stopped after $20 \mathrm{~min}$ at room temperature. The absorbance at $450 \mathrm{~nm}$ was measured with a plate reader, and the BDNF concentration in the tissue was assessed by comparing the values to the prepared standard curve.

\section{Data analysis}

All data were expressed as mean \pm S.E.M. The data obtained from various groups were statistically analyzed using two-way analysis of variance (ANOVA) followed by the post hoc Tukey's multiple comparison test. The value of $\mathrm{p}<0.05$ was considered as statistically significant.

\section{RESULTS}

\section{Depressive-like behavior induced by CMS in rats}

After 4-week CMS, a CMS $\times$ time interaction [group $\times$ time: $F(4,255)=27.98, p<0.001]$ was observed for the change of body weight of the rats (Figure 1B). The CMS significantly decreased the rate of body weight gain over the 28 day procedure [group: $\mathrm{F}(1,255)=5.74, \mathrm{p}=0.019$ ]. In addition, the stressed rats showed significantly lower locomotor activity than their control counterparts $(\mathrm{p}<0.05)$. In the comparison of sucrose consumption, there was a CMS $\times$ time interaction [group $\times$ time: $F(1,60)=7.15, p=0.01]$. As can be seen in Figure 1C, the CMS 
rats showed significantly lower sucrose consumption than their control counterparts ( $\mathrm{p}=0.004$ ), suggesting that CMS modeled anhedonia-like behavior of depressive phenotype in rats.

\section{Effects of treatment with 7,8-DHF on behavioral and biochemical parameters in stressed rats and controls}

\section{Body weight}

After 3-week treatment with 7,8-DHF, two-way ANOVA revealed that there were no effects of the CMS condition or treatment with 7,8-DHF on body weight (Figure 1D).

\section{Sucrose consumption test}

After 1-week treatment with 7,8-DHF, a CMS $\times 7,8$-DHF interaction [group $\times$ drug: $\mathrm{F}(2,60)=7.35, \mathrm{p}=0.001$ ] (Figure $2 \mathrm{~A}$ ) was observed. Post-hoc tests confirmed that in the stressed rats, the 7,8-DHF $20 \mathrm{mg} / \mathrm{kg}$ condition caused a greater increase in sucrose consumption than the 7,8-DHF $5 \mathrm{mg} / \mathrm{kg}$ and DMSO vehicle conditions $(\mathrm{p}<0.001)$.

In addition, stressed rats treated with 7,8-DHF at $20 \mathrm{mg} / \mathrm{kg}$ had significantly greater sucrose consumption than their control counterparts $(\mathrm{p}<0.01)$. After 3-week treatment with 7,8DHF, there were main effects of the CMS condition [group: $\mathrm{F}(1,57)=5.94, \mathrm{p}=0.018$ ] and treatment with 7,8-DHF [drug: $\mathrm{F}(2,57)=30.98, \mathrm{p}<0.001$ ] (Figure 2B). Post-hoc tests revealed that an injection of $20 \mathrm{mg} / \mathrm{kg} 7,8-\mathrm{DHF}$ was able to significantly increase the sucrose consumption in both the stressed and control rats. In addition, the stressed rats treated with 7,8-DHF at $20 \mathrm{mg} / \mathrm{kg}$ had significantly greater sucrose consumption than their control counterparts $(\mathrm{p}<0.05)$.

\section{Locomotor activity}

Main effects of the CMS condition [group: $F(1,52)=10.60$, $\mathrm{p}=0.002$ ] and treatment with 7,8-DHF [drug: $\mathrm{F}(2,52)=8.75$, $\mathrm{p}<0.001$ ] (Figure $3 \mathrm{~A}$ ) were shown in the locomotor activities of the rats. A subsequent analysis revealed that the control rats showed no difference in locomotion activity under either the DMSO vehicle or the 7,8-DHF conditions. Post-hoc tests confirmed that the stressed rats exhibited a greater locomotion activity under the 7,8-DHF $20 \mathrm{mg} / \mathrm{kg}$ condition than when under either the 7,8-DHF $5 \mathrm{mg} / \mathrm{kg}$ or DMSO vehicle conditions $(\mathrm{p}<0.01)$.

\section{Forced-swimming test}

Regarding the immobility counts in the FST, a CMS $\times 7,8$ DHF interaction [group $\times$ drug: $\mathrm{F}(2,58)=4.26, \mathrm{p}=0.019$ ] (Figure 3B) was observed. Post-hoc tests confirmed that in the stressed rats, the 7,8 -DHF $5 \mathrm{mg} / \mathrm{kg}$ condition caused a greater reduction in the immobility counts than the 7,8-DHF $20 \mathrm{mg} / \mathrm{kg}$ and DMSO vehicle conditions $(\mathrm{p}<0.01)$. The stressed rats treated with 7,8-DHF at $5 \mathrm{mg} / \mathrm{kg}$ showed significantly lower immobility counts than their control counterparts $(p<0.001)$. For the

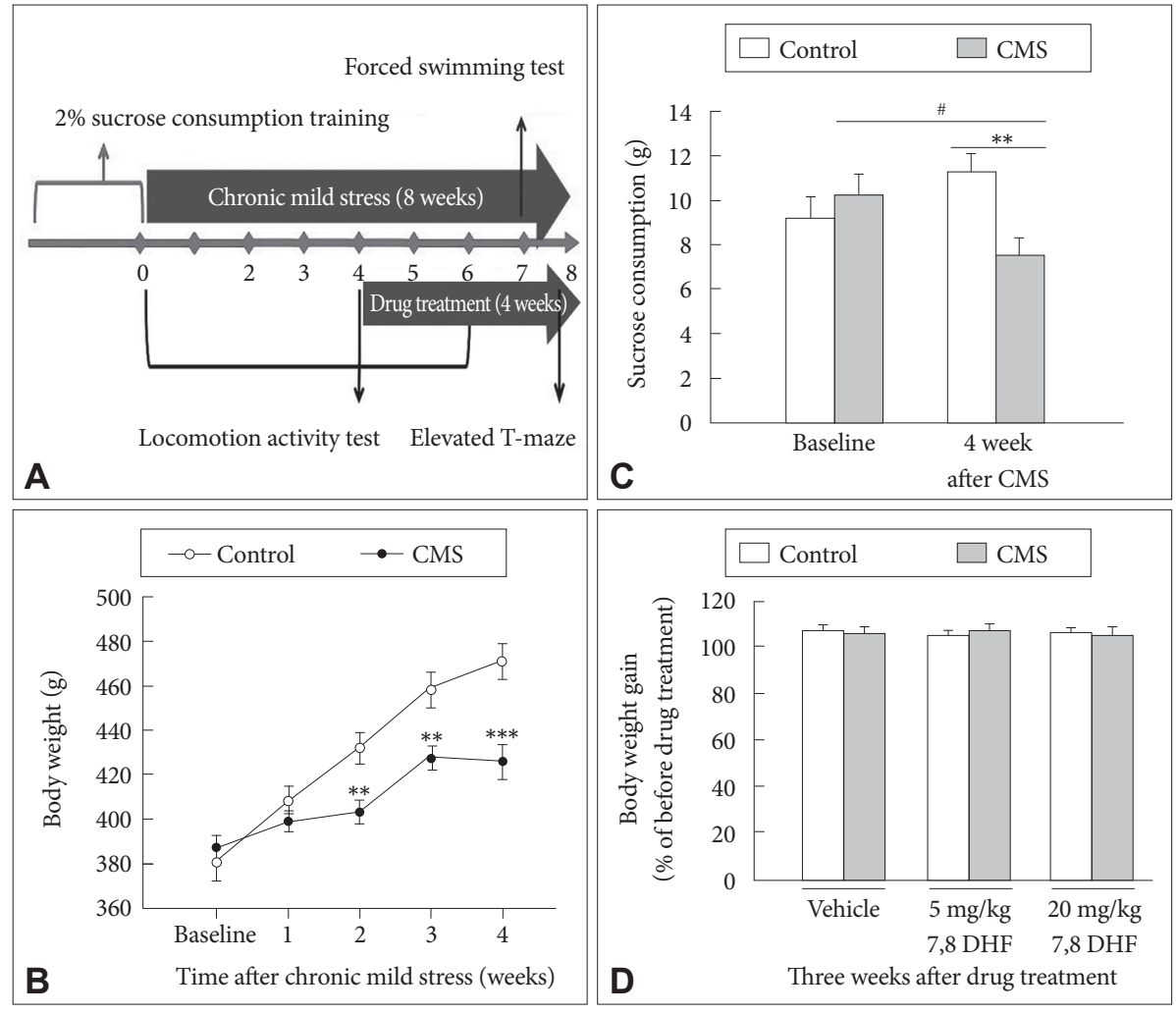

Figure 1. Behavioral effects of the 4 week CMS. A: The CMS protocol involved subjecting animals to 8 week CMS. After 4 week CMS, animals were treated with 7,8 -DHF or vehicle injection. During 8 week CMS period, sucrose consumption test were carried out once a week, Locomotion activity tests in week 0,4 , and 6 , Forced swimming test in week 7 and elevated T-maze in week 8. B: The effect of 4 week CMS on body weight gain (C) Consumption of 2 $\%$ sucrose solution in rats exposure to 4 week CMS versus control rats. D: Body weight gain in the CMS rats and control rats treated with vehicle, 5 and $20 \mathrm{mg} /$ $\mathrm{kg} \mathrm{7,8-DHF}$ for three weeks. Values are presented as mean+SEM. ${ }^{*} p<0.05$, ${ }^{* *} p<0.01,{ }^{* * *} p<0.001$, the CMS group vs. control group. $\# p<0.05, \# p<0.01$, $\# \# \#<0.001$, compared within the CMS or control group. 
swimming counts in the FST, a CMS condition $\times 7,8$-DHF interaction [group $\times$ drug: $\mathrm{F}(2,58)=4.61, \mathrm{p}=0.014$ ] (Figure $3 \mathrm{C}$ ) was observed. The CMS rats treated with 7,8-DHF $5 \mathrm{mg} / \mathrm{kg}$ showed significantly higher swimming counts than their control counterparts $(\mathrm{p}<0.01)$. As for the climbing counts in the FST, a main effect of treatment with 7,8-DHF was shown [drug: $\mathrm{F}(2,52)=8.75, \mathrm{p}<0.001$ ] (Figure 3D). Post-hoc tests revealed that an injection of $20 \mathrm{mg} / \mathrm{kg} 7,8-\mathrm{DHF}$ was capable of significantly increasing the climbing counts in both the stressed and control rats $(\mathrm{p}<0.001)$.

\section{Elevated T-maze test}

In the baseline latencies measured in the ETM, there were no effects of the CMS condition [group: $\mathrm{F}(1,53)=0.07, \mathrm{p}=0.793$ ] or treatment with 7,8-DHF [drug: $\mathrm{F}(2,53)=1.89$, $\mathrm{p}=0.162$ ]. In the first avoidance (avoidance 1) latencies measured in the ETM, there was a CMS condition $\times 7,8$-DHF interaction

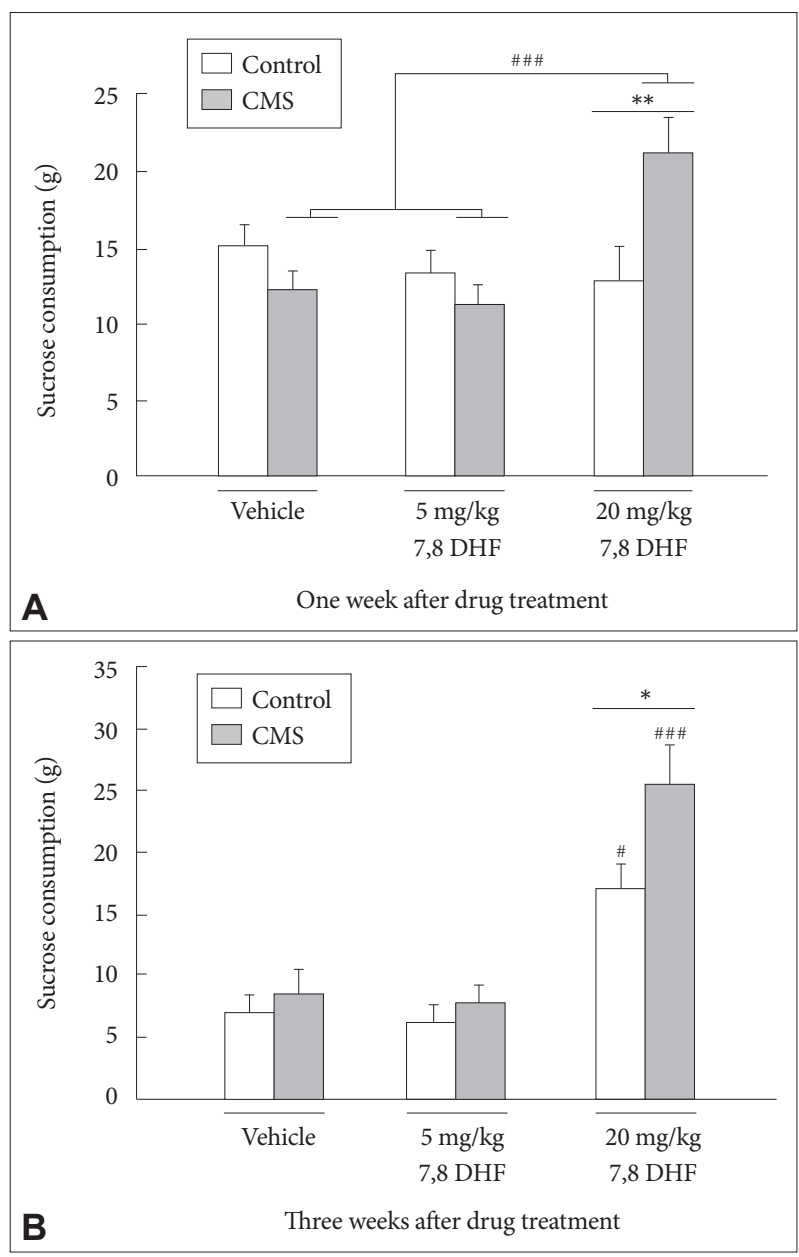

Figure 2. A: Consumption of $2 \%$ sucrose solution in the CMS rats and control rats treated with vehicle $(n=11), 5 \mathrm{mg} / \mathrm{kg}(\mathrm{n}=9)$ and 20 $\mathrm{mg} / \mathrm{kg}(\mathrm{n}=8)$ 7,8-DHF for one week and (B) for three weeks. Values are presented as mean+SEM. ${ }^{*} p<0.05,{ }^{* *} p<0.01,{ }^{* * *} p<0.001$, the CMS group vs. control group. $\# p<0.05$, \#\# $p<0.01$, \#\#\# $p<0.001$, compared within the CMS or control group. [group $\times$ drug: $\mathrm{F}(2,53)=3.61, \mathrm{p}=0.034$ ] with a main effect of treatment with 7,8-DHF [drug: $\mathrm{F}(2,53)=9.38, \mathrm{p}<0.001$ ] (Figure $4 \mathrm{~A})$. The DMSO vehicle-treated stressed rats had significantly greater avoidance 1 latencies than their control counterparts $(\mathrm{p}<0.05)$. The stressed rats treated with $20 \mathrm{mg} / \mathrm{kg}$ rather than 5 $\mathrm{mg} / \mathrm{kg} 7,8-\mathrm{DHF}$ had significantly lower avoidance 1 latencies than those treated with DMSO vehicle $(\mathrm{p}<0.05)$. For the oneway escape latencies in the ETM, there were no effects of the CMS condition or treatment with 7,8-DHF (Figure 4B).

\section{Hippocampal BDNF levels}

In the hippocampal BDNF concentrations, there existed a main effect of the CMS condition [group: $\mathrm{F}(1,12)=6.15$, $\mathrm{p}=0.029$ ] (Figure 5A). The DMSO vehicle-treated stressed rats had significantly lower BDNF levels than controls $(\mathrm{p}<0.01)$. In the stressed rats, the 7,8-DHF, when given at $5 \mathrm{mg} / \mathrm{kg}$ but not $20 \mathrm{mg} / \mathrm{kg}$, significantly increased the BDNF levels. The control rats exhibited no significant difference in BDNF levels under either the DMSO vehicle condition or treatment with either doses of 7,8-DHF.

\section{Serum corticosterone levels}

In the serum corticosterone levels, there existed a CMS $\times 7,8$ DHF interaction [group $\times$ drug: $F(2,28)=5.26, \mathrm{p}=0.011$ ] with a main effect in the CMS condition [group: $F(1,28)=16.74$, $\mathrm{p}<0.001$ )] (Figure 5B) and treatment with different doses of 7,8-DHF [drug: $\mathrm{F}(2,28)=33.75, \mathrm{p}<0.001$ ]. The DMSO vehicletreated stressed rats had significantly higher corticosterone levels than controls. 7,8-DHF dose-dependently reduced the corticosterone levels of the stressed rats, with greatest levels in the DMSO vehicle condition, intermediate levels in the 7,8DHF $5 \mathrm{mg} / \mathrm{kg}$ condition, and lowest levels in the 7,8-DHF 20 $\mathrm{mg} / \mathrm{kg}$ condition $(\mathrm{p}<0.001)$. For the control rats, the treatment with $20 \mathrm{mg} / \mathrm{kg}$ 7,8-DHF, compared to the treatment with the DMSO vehicle $(\mathrm{p}<0.05)$, was capable of significantly reducing the corticosterone levels.

\section{DISCUSSION}

In the present study, 7,8-DHF reversed the CMS-induced depressive-like and partial anxiety-like behaviors. Moreover, 7,8-DHF significantly increased the CMS-subjected rats' hippocampal BDNF levels and reduced their serum corticosterone levels, which may underlie the antidepressant and/or partial anxiolytic efficacy of the treatment.

The most striking finding of our study is that the CMS-induced anhedonia-like behavior was reversed after 7 days of the 7,8-dihydroxyflavone $(20 \mathrm{mg} / \mathrm{kg})$ treatment, and remained so across the subsequent treatment regime. In accordance with our finding, Zhang et al. ${ }^{39}$ even detected the effect of a single 
dose of 7,8-DHF to improve the decreased sucrose preference 1 day after administration in the social defeat stress model of depression. Conventional antidepressants that target monoaminergic systems and increase the synthesis of BDNF typically take several weeks to be effective. Although the time-lag between the drug administration and its therapeutic effect is not clearly understood, it may be partly explained by the BDNF-TrkB positive feedback mechanism, which is a protracted process. ${ }^{40}$ Specifically, BDNF binding to TrkB at synaptic sites leads to the internalization of the BDNF-TrkB complex, which is endocyted and retrograde transported from spines to cell bodies, where it activates the synthesis of more BDNF. By skipping this process and directly activating TrkB, 7,8-DHF may thereby produce a fast-onset antidepressant effect. This effect is also supported by a recent study reporting that the antidepressant effect of 7,8-DHF is in part mediated via mammalian target of rapamycin complex 1 (mTORC1) signaling, ${ }^{41}$ which is known to be implicated in the rapid antidepressant action of the N-methyl-D-aspartate (NMDA) receptor antagonist ketamine. ${ }^{42,43}$

We also noted the phenomenon that after repeated injections, the baseline of vehicle group has shifted, thus the difference between CMS and control rats become less apparent. The phenomenon has been reported previously, ${ }^{44}$ and is possibly due to the fact that the repeated injection itself (regarded as a predictable stress) may also change the hedonic state-this is particularly dominant in the already stressed rats (i.e., the CMS rats), which can be interpreted as a stress-coping over consumption. ${ }^{44}$

Our study demonstrated that the administration of 7,8-DHF ( $5 \mathrm{mg} / \mathrm{kg}$, i.p.) significantly reduced the despair behavior in the FST, without altering locomotor activity. An earlier report showed that chronic treatment of 7,8-DHF ( $5 \mathrm{mg} / \mathrm{kg}$ ) for 21 days via oral administration evidently reduced the immobility in FST in mice. ${ }^{18}$ In a recent study using the social defeat stress model of depression, a single dose of 7,8-DHF (10 mg/kg, i.p.) attenuated an increased immobility time in depressed mice 3 hours after administration. ${ }^{39}$ These findings together with ours imply that 7,8-DHF could be a curative treatment for CMS induced depressive-like behaviors in rats. Interestingly, a recent study reported that intracerebroventricular infusion of 7,8DHF (240 ng/day) served to completely prevent the rats from developing anhedonia after being exposed to the CMS proto$\mathrm{col},{ }^{19}$ suggesting a role of 7,8-DHF in prophylactic treatment. Collectively, all these findings indicate the important role of BDNF-TrkB signaling in the both the action of antidepressants and the development of depression. ${ }^{2-5}$

Unexpectedly, treatment with the larger dose of 7,8-DHF $(20 \mathrm{mg} / \mathrm{kg}$ ) had no effect on despair behavior. It is possible that this regime possesses psychostimulant effects, as evidenced by

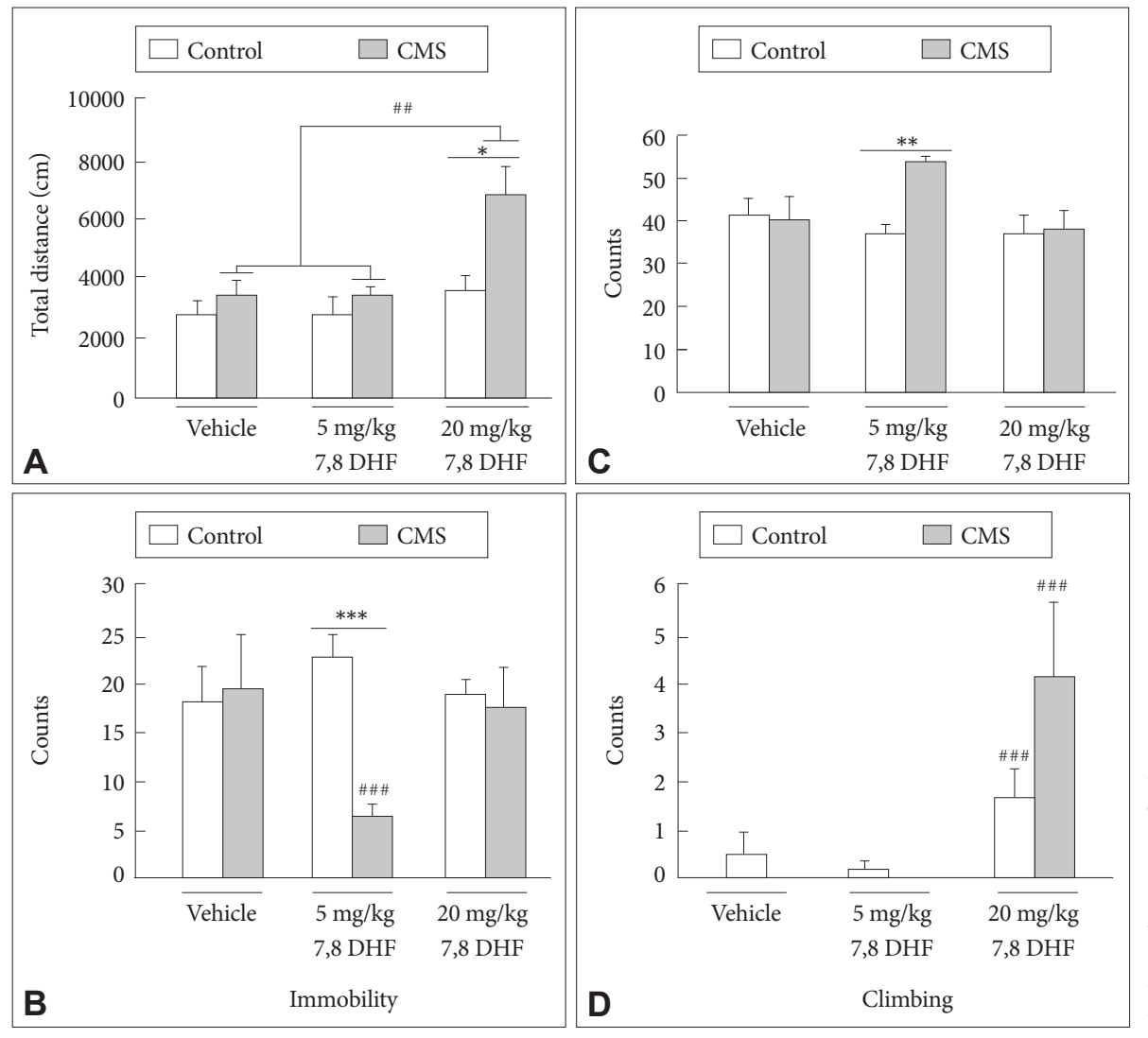

Figure 3. A: Locomotor activities in the CMS rats and control rats treated with vehicle and different 7,8-DHF dosages for 2 weeks. B: Immobility, C: swimming, and (D) climbing time in FST in the CMS rats and control rats treated with vehicle and different 7,8-DHF dosages for 3 weeks. The data represent the mean+ SEM. ${ }^{*} p<0.05$, the CMS group vs. control group. ${ }^{\#} p<0.01$, compared within the CMS or control group. 
its ability to increase locomotor activity (Figure 3A), thus specifically increasing climbing behavior instead of immobility in the FST. It is also possible that, for reducing despair behavior, either the effective dose range of 7,8-DHF is narrow or there exists a reverse dose-dependent relationship. Taken together, 7,8-DHF being capable of effectively treating different parts of the depressive phenotype at different doses supports the idea that it has significant antidepressant potential. Future study is suggested to verify if 7,8-DHF at an intermediate dose (i.e. between $5 \mathrm{mg} / \mathrm{kg}$ and $20 \mathrm{mg} / \mathrm{kg}$, i.p.) can simultaneously treat both anhedonia and despair behavior.

Significantly greater general anxiety-like behaviors were observed in the CMS-subjected rats compared to controls, which were not attributed to reduced locomotor activity as there was no between-group difference in locomotor activity. On the other hand, the CMS-subjected rats did not display a significant increase in panic-like behavior compared to controls.

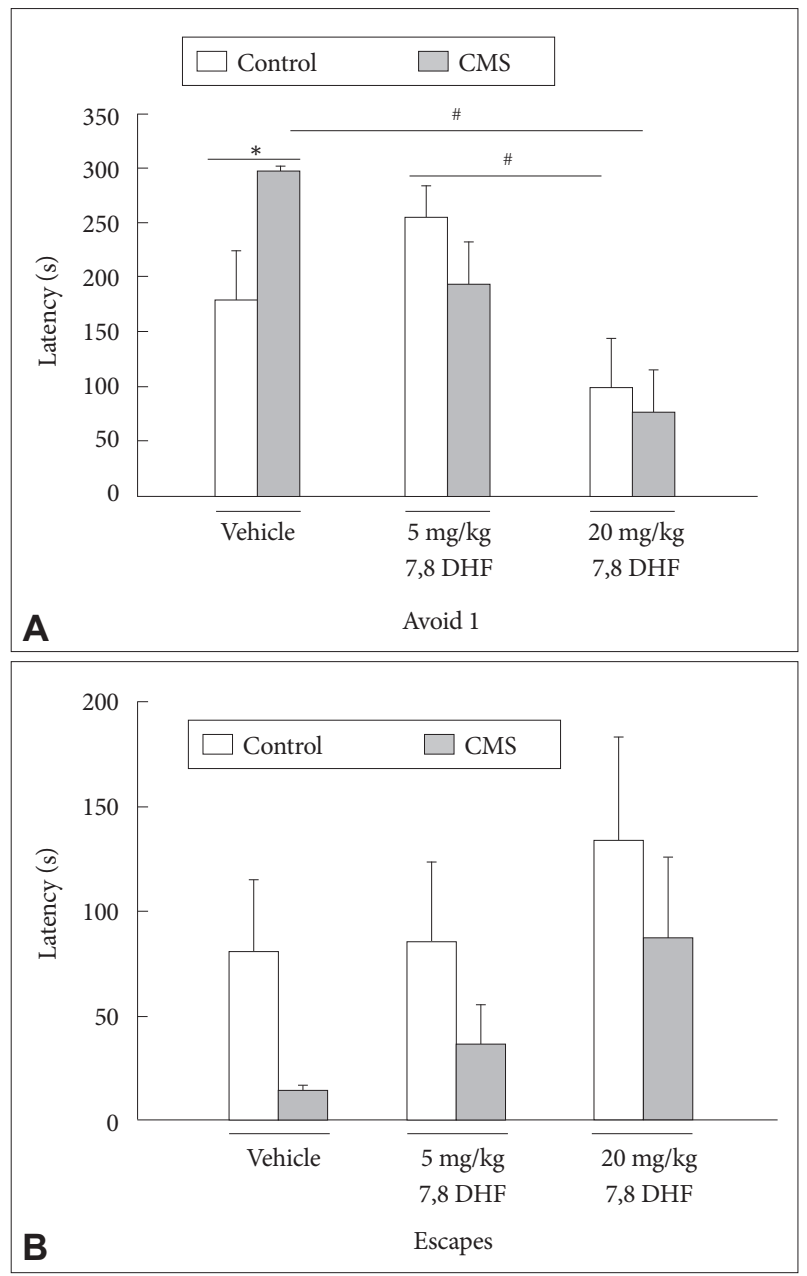

Figure 4. A: The latencies to leave the enclosed arm and (B) the open arm were measured from the CMS rats and control rats treated with vehicle and different 7,8-DHF dosages for 4 weeks. Result are presented as mean+SEM. ${ }^{*} p<0.05$, the CMS group vs. control group. ${ }^{*} p<0.05$, compared within the CMS or control group.
Previous studies have shown conflicting results related to the anxiety-like behavior in the CMS paradigm, such as no effect, ${ }^{45}$ anxiogenic effect, ${ }^{46}$ and partial anxiolytic effect. ${ }^{47}$ The reason for the discrepancy may be attributed to the strain of the animal, condition of the test, and the duration of CMS exposure. Failure of the CMS paradigm to induce panic-like behavior in our stressed rats may result from high inter-individual variability in escape latencies measured in the ETM (Figure $4 \mathrm{~B})$. It is also possible that the duration of CMS exposure is not sufficient to generate a stable panic-like behavior in our stressed rats.

Although the treatment with 7,8-DHF at any dose has no effect on one-way escape (reflecting no panicolytic-like effect of this drug), 7,8-DHF at $20 \mathrm{mg} / \mathrm{kg}$ treatment in the stressed rats significantly reduced their avoidance latencies. Contrary
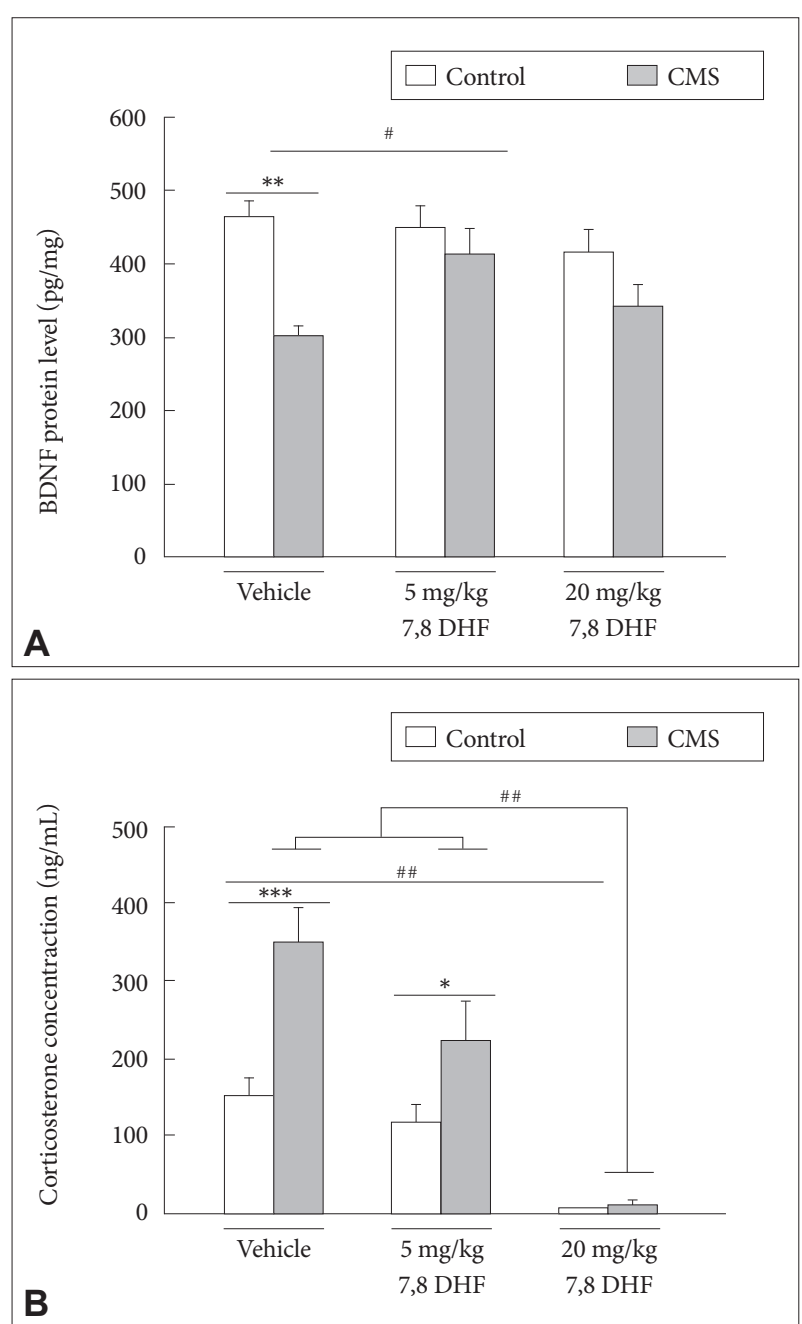

Figure 5. A: The BDNF protein level in hippocampus and (B) serum corticosterone level in the CMS rats and control rats treated with vehicle and different 7,8-DHF dosages for 3 weeks. Data represent mean+SEM. ${ }^{*} p<0.05,{ }^{* *} p<0.01,{ }^{* * *} p<0.001$, the CMS group vs. control group. ${ }^{*} p<0.05$, ${ }^{\#} p<0.01$, compared within the CMS or control group. 
to an earlier report demonstrating no effect of 7,8-DHF on ratsanxiety-like behavior on an elevated plus maze, ${ }^{27}$ our study is the first to provide evidence suggesting that 7,8-DHF may exert potential anxiolytic-like effect in stressed rats. However, this finding should be interpreted with caution because this drug at a dose of at $20 \mathrm{mg} / \mathrm{kg}$ also significantly increased locomotor activity; therefore we could not exclude the possibility that psychostimulant effects might be responsible for their behavioral effects on avoidance latencies measured in the ETM.

In accordance with a recent study reporting the CMS-induced biochemical alternations, ${ }^{48}$ the result of our study showed elevated serum corticosterone levels and decreased hippocampal BDNF levels in the CMS-subjected rats. The finding suggested an interplay between the two neurochemical parameters in the stressed rats and cohered with earlier reports describing HPA axis hyperactivation linking to low hippocampal BDNF level. ${ }^{49,50}$ Specifically, stress-induced elevated corticosteroids have detrimental effects on regulating the function and structure of the hippocampus, possibly through alterations in the expression of hippocampal BDNF. ${ }^{51}$ For example, repeated corticosterone treatment resulted in a graded increase in depression-like behavior, which is associated with decreased hippocampal neurogenesis and BDNF levels. ${ }^{52}$ Interestingly, reduced hippocampal $\mathrm{BDNF}$ per se is not sufficient to mediate depression-like behavior, ${ }^{53}$ but resulted in a depressive phenotype when combined with stress exposure..$^{54}$ It is known that hippocampal neurogenesis plays an important role in regulating depression-like behavior ${ }^{55}$ while stress-induced decreases in hippocampal neurogenesis have been proposed to contribute to the pathophysiology of depression. ${ }^{56}$ Thus, our finding that combined HPA axis hyperactivation and low hippocampal BDNF levels, possibly contributing to decreased hippocampal neurogenesis, provided an underlying mechanism for CMS paradigm to induce depressive phenotype in rats.

In the present study, administration of 7,8-DHF dose-dependently reduced the corticosterone levels and when given at $5 \mathrm{mg} / \mathrm{kg}$, increased the hippocampal BDNF levels in the CMSsubjected rats. The elevation in the HPA functioning following the exposure to CMS might be the cause of the reduction in hippocampal BDNF levels; ${ }^{35,52}$ treatment with 7,8-DHF probably restored the CMS-induced HPA axis alterations, which in turn might rescue the reduction in hippocampal BDNF levels. ${ }^{57}$ It is also possible that 7,8-DHF per se increases BDNF levels. Specifically, Wu et al. ${ }^{58}$ suggested that 7,8-DHF may trigger further BDNF production via a positive feedback mechanism, in which an initial enhancement of TrkB phosphorylation following 7,8-DHF treatment may activate the PI3K/Akt pathway, stimulating the synthesis of BDNF via cAMP response element-binding protein (CREB), which is an important transcription factor needed to regulate BDNF transcrip- tion. ${ }^{59}$ The higher dose of 7,8-DHF (20 mg/kg), however, was less efficient in increasing the BDNF levels. It is possible that high concentrations of TrkB ligands resulted in a down-regulation of the $\operatorname{TrkB}$ response, ${ }^{60}$ and thus caused a decrease in the positive feedback mechanism. Another possibility is that the different pharmacological effects of flavonoids depend on their concentration. ${ }^{61}$ For example, Akt activation is induced by lower concentrations of the flavonoid quercetin and inhibited by higher concentrations. ${ }^{62}$ Collectively, the modulation of both HPA axis activity and BDNF levels may be responsible for the antidepressant efficacy of 7,8-DHF in the rat model of CMS. There is much data from animal studies pointing out promising results of 7,8-DHF to treat Alzheimer's disease, ${ }^{15,17}$ Parkinson disease $\mathrm{e}^{14}$ and PTSD. ${ }^{25,26}$ Effects of neuroprotection, neurogenesis, synaptogenesis and normalization of BDNFTrkB signaling were proposed action mechanisms in common. Together with our data indicate that 7,8-DHF may act as a powerful therapeutic tool for the treatment of various neuropsychiatric disorders including depression.

The current study was limited in the lack of phosphorylated TrKB receptor to fully confirm that 7,8-DHF activates TrkB signaling. Western blot or immunohistochemistry with $\mathrm{p}$ TrkB and p-Akt antibodies should be carried out in the future study. Nevertheless, the effects of 7,8-DHF could be still confirmed by behavioral and neuroendocrinological indexes, as seen in the behavioral tests, serum corticosterone, and BDNF levels.

In conclusion, our study offers a novel therapeutic approach to depression: a TrkB agonist, 7,8-DHF. It possesses a fast-onset antidepressant effect and a partial anxiolytic effect. Most importantly, chronic systemic treatment with this drug has the benefit of being more feasible and less invasive than viral or recombinant protein delivery, and allows the chronic targeting of neural pathologies of depression where BDNF levels and HPA axis activity are dysregulated.

\section{Acknowledgments}

This study was supported in part by grants from the Ministry of Science and Technology of Taiwanese Government (MOST-103-2314-B-016-021) and the Tri-Service General Hospital Grant (TSGH-C104-128), and the National Defense Medical Research (MAB-104-007 and MAB-104-008).

\section{REFERENCES}

1. Johnson JE, Barde YA, Schwab M, Thoenen H. Brain-derived neurotrophic factor supports the survival of cultured rat retinal ganglion cells. J Neurosci 1986;6:3031-3038.

2. Castren E. Neuronal network plasticity and recovery from depression. JAMA Psychiatry 2013;70:983-989.

3. Molendijk ML, Bus BA, Spinhoven P, Penninx BW, Kenis G, Prickaerts J, et al. Serum levels of brain-derived neurotrophic factor in major depressive disorder: state-trait issues, clinical features and pharmacological treatment. Mol Psychiatry 2011;16:1088-1095.

4. Taliaz D, Stall N, Dar DE, Zangen A. Knockdown of brain-derived 
neurotrophic factor in specific brain sites precipitates behaviors associated with depression and reduces neurogenesis. Mol Psychiatry 2010; 15:80-92.

5. Angelucci F, Brene S, Mathe AA. BDNF in schizophrenia, depression and corresponding animal models. Mol Psychiatry 2005;10:345-352.

6. Kerman IA. New insights into BDNF signaling: relevance to major depression and antidepressant action. Am J Psychiatry 2012;169:11371140.

7. Gentry JJ, Barker PA, Carter BD. The p75 neurotrophin receptor: multiple interactors and numerous functions. Prog Brain Res 2004;146:2539.

8. Gan WB. TrkB works at postsynaptic sites. Neuron 1999;24:491-492.

9. Black IB. Trophic regulation of synaptic plasticity. J Neurobiol 1999;41: 108-118.

10. Lee J, Duan W, Mattson MP. Evidence that brain-derived neurotrophic factor is required for basal neurogenesis and mediates, in part, the enhancement of neurogenesis by dietary restriction in the hippocampus of adult mice. J Neurochem 2002;82:1367-1375.

11. Ernfors P, Bramham CR. The coupling of a trkB tyrosine residue to LTP. Trends Neurosci 2003;26:171-173.

12. Poduslo JF, Curran GL. Permeability at the blood-brain and bloodnerve barriers of the neurotrophic factors: NGF, CNTF, NT-3, BDNF. Brain Res Mol Brain Res 1996;36:280-286.

13. Massa SM, Yang T, Xie Y, Shi J, Bilgen M, Joyce JN, et al. Small molecule BDNF mimetics activate TrkB signaling and prevent neuronal degeneration in rodents. J Clin Invest 2010;120:1774-1785.

14. Jang SW, Liu X, Yepes M, Shepherd KR, Miller GW, Liu Y, et al. A selective TrkB agonist with potent neurotrophic activities by 7,8-dihydroxyflavone. Proc Natl Acad Sci U S A 2010;107:2687-2692.

15. Devi L, Ohno M. 7,8-dihydroxyflavone, a small-molecule TrkB agonist, reverses memory deficits and BACE1 elevation in a mouse model of Alzheimer's disease. Neuropsychopharmacology 2012;37:434-444.

16. Zeng Y, Liu Y, Wu M, Liu J, Hu Q. Activation of TrkB by 7,8-dihydroxyflavone prevents fear memory defects and facilitates amygdalar synaptic plasticity in aging. J Alzheimers Dis 2012;31:765-778.

17. Zhang Z, Liu X, Schroeder JP, Chan CB, Song M, Yu SP, et al. 7,8-dihydroxyflavone prevents synaptic loss and memory deficits in a mouse model of Alzheimer's disease. Neuropsychopharmacology 2014;39:638650

18. Liu X, Chan CB, Jang SW, Pradoldej S, Huang J, He K, et al. A synthetic 7,8-dihydroxyflavone derivative promotes neurogenesis and exhibits potent antidepressant effect. J Med Chem 2010;53:8274-8286.

19. Blugeot A, Rivat C, Bouvier E, Molet J, Mouchard A, Zeau B, et al. Vulnerability to depression: from brain neuroplasticity to identification of biomarkers. J Neurosci 2011;31:12889-12899.

20. Bielajew C, Konkle AT, Merali Z. The effects of chronic mild stress on male Sprague-Dawley and Long Evans rats: I. Biochemical and physiological analyses. Behav Brain Res 2002;136:583-592.

21. Liu D, Xie K, Yang X, Gu J, Ge L, Wang X, et al. Resveratrol reverses the effects of chronic unpredictable mild stress on behavior, serum corticosterone levels and BDNF expression in rats. Behav Brain Res 2014;264:9-16

22. Ballenger JC. Clinical guidelines for establishing remission in patients with depression and anxiety. J Clin Psychiatry 1999;60(Suppl 22):2934.

23. Hashimoto K, Shimizu E, Iyo M. Critical role of brain-derived neurotrophic factor in mood disorders. Brain Res Brain Res Rev 2004;45:104114.

24. Middeldorp CM, Slof-Op 't Landt MC, Medland SE, van Beijsterveldt $\mathrm{CE}$, Bartels M, Willemsen G, et al. Anxiety and depression in children and adults: influence of serotonergic and neurotrophic genes? Genes Brain Behav 2010;9:808-816.

25. Baker-Andresen D, Flavell CR, Li X, Bredy TW. Activation of BDNF signaling prevents the return of fear in female mice. Learn Mem 2013;20:237-240.
26. Andero R, Ressler KJ. Fear extinction and BDNF: translating animal models of PTSD to the clinic. Genes Brain Behav 2012;11:503-512.

27. Castello NA, Nguyen MH, Tran JD, Cheng D, Green KN, LaFerla FM. 7,8-Dihydroxyflavone, a small molecule TrkB agonist, improves spatial memory and increases thin spine density in a mouse model of Alzheimer disease-like neuronal loss. PLoS One 2014;9:e91453.

28. Viana MB, Tomaz C, Graeff FG. The elevated T-maze: a new animal model of anxiety and memory. Pharmacol Biochem Behav 1994;49:549554.

29. Zangrossi H Jr, Graeff FG. Behavioral validation of the elevated Tmaze, a new animal model of anxiety. Brain Res Bull 1997;44:1-5.

30. Willner P. Validity, reliability and utility of the chronic mild stress model of depression: a 10-year review and evaluation. Psychopharmacology (Berl) 1997;134:319-329.

31. Willner P. Chronic mild stress (CMS) revisited: consistency and behavioural-neurobiological concordance in the effects of CMS. Neuropsychobiology 2005;52:90-110.

32. Grippo AJ, Beltz TG, Johnson AK. Behavioral and cardiovascular changes in the chronic mild stress model of depression. Physiol Behav 2003;78:703-710.

33. Becker C, Zeau B, Rivat C, Blugeot A, Hamon M, Benoliel JJ. Repeated social defeat-induced depression-like behavioral and biological alterations in rats: involvement of cholecystokinin. Mol Psychiatry 2008;13: 1079-1092.

34. Nibuya M, Nestler EJ, Duman RS. Chronic antidepressant administration increases the expression of cAMP response element binding protein (CREB) in rat hippocampus. J Neurosci 1996;16:2365-2372.

35. Smith MA, Makino S, Kvetnansky R, Post RM. Stress and glucocorticoids affect the expression of brain-derived neurotrophic factor and neurotrophin-3 mRNAs in the hippocampus. J Neurosci 1995;15:17681777.

36. Nibuya M, Morinobu S, Duman RS. Regulation of BDNF and trkB mRNA in rat brain by chronic electroconvulsive seizure and antidepressant drug treatments. J Neurosci 1995;15:7539-7547.

37. Russo-Neustadt A, Beard RC, Cotman CW. Exercise, antidepressant medications, and enhanced brain derived neurotrophic factor expression. Neuropsychopharmacology 1999;21:679-682.

38. Szapacs ME, Mathews TA, Tessarollo L, Ernest Lyons W, Mamounas LA, Andrews AM. Exploring the relationship between serotonin and brain-derived neurotrophic factor: analysis of BDNF protein and extraneuronal 5-HT in mice with reduced serotonin transporter or BDNF expression. J Neurosci Methods 2004;140:81-92.

39. Zhang JC, Yao W, Dong C, Yang C, Ren Q, Ma M, et al. Comparison of ketamine, 7,8-dihydroxyflavone, and ANA-12 antidepressant effects in the social defeat stress model of depression. Psychopharmacology (Berl) 2015;232:4325-4335.

40. Wyneken U, Sandoval M, Sandoval S, Jorquera F, Gonzalez I, Vargas F, et al. Clinically relevant doses of fluoxetine and reboxetine induce changes in the TrkB content of central excitatory synapses. Neuropsychopharmacology 2006;31:2415-2423.

41. Zhang JC, Wu J, Fujita Y, Yao W, Ren Q, Yang C, et al. Antidepressant effects of TrkB ligands on depression-like behavior and dendritic changes in mice after inflammation. Int J Neuropsychopharmacol 2014;18.

42. Li N, Lee B, Liu RJ, Banasr M, Dwyer JM, Iwata M, et al. mTOR-dependent synapse formation underlies the rapid antidepressant effects of NMDA antagonists. Science 2010;329:959-964.

43. Li N, Liu RJ, Dwyer JM, Banasr M, Lee B, Son H, et al. Glutamate Nmethyl-D-aspartate receptor antagonists rapidly reverse behavioral and synaptic deficits caused by chronic stress exposure. Biol Psychiatry 2011;69:754-761.

44. Yang SN, Wang YH, Tung CS, Ko CY, Liu YP. Effects of escitalopram on a rat model of persistent stress-altered hedonic activities: towards a new understanding of stress and depression. Chin J Physiol 2015;58: 404-411. 
45. Matuszewich L, Karney JJ, Carter SR, Janasik SP, O’Brien JL, Friedman $\mathrm{RD}$. The delayed effects of chronic unpredictable stress on anxiety measures. Physiol Behav 2007;90:674-681.

46. Bondi CO, Rodriguez G, Gould GG, Frazer A, Morilak DA. Chronic unpredictable stress induces a cognitive deficit and anxiety-like behavior in rats that is prevented by chronic antidepressant drug treatment. Neuropsychopharmacology 2008;33:320-331.

47. Kompagne H, Bardos G, Szenasi G, Gacsalyi I, Harsing LG, Levay G. Chronic mild stress generates clear depressive but ambiguous anxietylike behaviour in rats. Behav Brain Res 2008;193:311-314.

48. Jindal A, Mahesh R, Bhatt S. Etazolate rescues behavioral deficits in chronic unpredictable mild stress model: modulation of hypothalamic-pituitary-adrenal axis activity and brain-derived neurotrophic factor level. Neurochem Int 2013;63:465-475.

49. Xu Y, Ku B, Tie L, Yao H, Jiang W, Ma X, et al. Curcumin reverses the effects of chronic stress on behavior, the HPA axis, BDNF expression and phosphorylation of CREB. Brain Res 2006;1122:56-64.

50. Zheng H, Liu Y, Li W, Yang B, Chen D, Wang X, et al. Beneficial effects of exercise and its molecular mechanisms on depression in rats. Behav Brain Res 2006;168:47-55.

51. Schaaf MJ, De Kloet ER, Vreugdenhil E. Corticosterone effects on BDNF expression in the hippocampus. Implications for memory formation. Stress 2000;3:201-208.

52. Yau SY, Lau BW, Tong JB, Wong R, Ching YP, Qiu G, et al. Hippocampal neurogenesis and dendritic plasticity support running-improved spatial learning and depression-like behaviour in stressed rats. PLoS One 2011;6:e24263.

53. Adachi M, Barrot M, Autry AE, Theobald D, Monteggia LM. Selective loss of brain-derived neurotrophic factor in the dentate gyrus attenuates antidepressant efficacy. Biol Psychiatry 2008;63:642-649.

54. Duman CH, Schlesinger L, Kodama M, Russell DS, Duman RS. A role for MAP kinase signaling in behavioral models of depression and antidepressant treatment. Biol Psychiatry 2007;61:661-670.

55. Santarelli L, Saxe M, Gross C, Surget A, Battaglia F, Dulawa S, et al. Requirement of hippocampal neurogenesis for the behavioral effects of antidepressants. Science 2003;301:805-809.

56. Gould E, Gross CG. Neurogenesis in adult mammals: some progress and problems. J Neurosci 2002;22:619-623.

57. Mitsukawa K, Mombereau C, Lotscher E, Uzunov DP, van der Putten $\mathrm{H}$, Flor PJ, et al. Metabotropic glutamate receptor subtype 7 ablation causes dysregulation of the HPA axis and increases hippocampal BDNF protein levels: implications for stress-related psychiatric disorders. Neuropsychopharmacology 2006;31:1112-1122.

58. Wu CH, Hung TH, Chen CC, Ke CH, Lee CY, Wang PY, et al. Post-injury treatment with 7,8-dihydroxyflavone, a TrkB receptor agonist, protects against experimental traumatic brain injury via PI3K/Akt signaling. PLoS One 2014;9:e113397.

59. Lonze BE, Ginty DD. Function and regulation of CREB family transcription factors in the nervous system. Neuron 2002;35:605-623.

60. Sommerfeld MT, Schweigreiter R, Barde YA, Hoppe E. Down-regulation of the neurotrophin receptor TrkB following ligand binding. Evidence for an involvement of the proteasome and differential regulation of TrkA and TrkB. J Biol Chem 2000;275:8982-8990.

61. Kong AN, Yu R, Chen C, Mandlekar S, Primiano T. Signal transduction events elicited by natural products: role of MAPK and caspase pathways in homeostatic response and induction of apoptosis. Arch Pharm Res 2000;23:1-16.

62. Granado-Serrano AB, Martin MA, Bravo L, Goya L, Ramos S. Quercetin induces apoptosis via caspase activation, regulation of $\mathrm{Bcl}-2$, and inhibition of PI-3-kinase/Akt and ERK pathways in a human hepatoma cell line (HepG2). J Nutr 2006;136:2715-2721. 